\title{
Two novel blue phosphorescent host materials containing phenothiazine-5,5-dioxide structure derivatives
}

\author{
Feng-Ming Xie ${ }^{1,2}$, Qingdong $\mathrm{Ou}^{3}$, Qiang Zhang ${ }^{1,2}$, Jiang-Kun Zhang ${ }^{1,2}$, Guo-Liang Dai, ${ }^{1,2}$ \\ Xin Zhao ${ }^{* 1,2}$ and Huai-Xin Wei ${ }^{* 1,2}$
}

\author{
Full Research Paper \\ Address: \\ ${ }^{1}$ College of Chemistry, Biology and Material Engineering, Suzhou \\ University of Science and Technology, Suzhou, Jiangsu 215009, P.R. \\ China, ${ }^{2}$ Jiangsu Key Laboratory of Environmental Functional \\ Materials, Suzhou, Jiangsu 215009, P.R. China and ${ }^{3}$ Department of \\ Materials Science and Engineering, Monash University, Clayton, \\ Victoria 3800 , Australia \\ Email: \\ Xin Zhao* - zhaoxinsz@126.com; Huai-Xin Wei ${ }^{*}$ - hxwei@usts.edu.cn \\ * Corresponding author \\ Keywords: \\ host materials; phenothiazine; phosphorescence; synthesis
}

Beilstein J. Org. Chem. 2018, 14, 869-874.

doi:10.3762/bjoc. 14.73

Received: 12 November 2017

Accepted: 03 April 2018

Published: 17 April 2018

This article is part of the Thematic Series "Recent advances in materials for organic light emitting diodes".

Guest Editor: E. Zysman-Colman

(C) 2018 Xie et al.; licensee Beilstein-Institut.

License and terms: see end of document.

\begin{abstract}
Two novel D-A bipolar blue phosphorescent host materials based on phenothiazine-5,5-dioxide: 3-(9H-carbazol-9-yl)-10-ethyl10H-phenothiazine-5,5-dioxide (CEPDO) and 10-butyl-3-(9H-carbazol-9-yl)-10H-phenothiazine-5,5-dioxide (CBPDO) were synthesized and characterized. The photophysical, electrochemical and thermal properties were systematically investigated. CEPDO and CBPDO not only have a high triplet energy but also show a bipolar behavior. Moreover, their fluorescence emission peaks are in the blue fluorescence region at $408 \mathrm{~nm}$ and the fluorescence quantum efficiency $(\Phi)$ of CEPDO and CBPDO were $62.5 \%$ and $59.7 \%$, respectively. Both CEPDO and CBPDO showed very high thermal stability with decomposition temperatures $\left(T_{\mathrm{d}}\right)$ of 409 and $396{ }^{\circ} \mathrm{C}$ as well as suitable HOMO and LUMO energy levels. This preferable performance suggests that CEPDO and CBPDO are alternative bipolar host materials for the PhOLEDs.
\end{abstract}

\section{Introduction}

Since 1987, the Tang group [1] firstly reported double organic light-emitting diodes (OLEDs) with ultra-thin film by using vacuum evaporation technology. It has attracted much attention to develop it. In recent years, OLEDs have been rapidly developed and widely used in lighting and display because of many unique performance advantages such as wide viewing angle $\left(\geq 170^{\circ}\right)$, fast response ( $1 \mu$ s scale), high luminous efficiency, low drive voltage (3-10 V), thickness (less than $2 \mathrm{~mm}$ ), lightweightness and flexibility [2-6]. Compared with traditional fluorescence OLEDs which only utilize singlet (25\%) excitons for electroluminescence, PhOLEDs can simultaneously harvest both the singlet and triplet (75\%) excitons through spin-orbit 
coupling (SOC), and obtain nearly $100 \%$ of the internal quantum efficiency (IQE). Thus, most of researchers have focused on phosphorescent organic light-emitting diodes (PhOLEDs) all over the world $[7,8]$. With the deepening of this research, the performance of red and green electroluminescent devices has been able to meet the commercial requirements, but the blue electroluminescent devices have several weaknesses such as low efficiency and poor stability and so on, which hinder its development. It has been proved that the selection of proper materials for each layer is very important for achieving highly efficient PhOLEDs. In particular, the design of host materials plays a critical role in the determination of the devices performance. Therefore, it is beneficial to develop new blue phosphorescent host materials with high-performance for blue PhOLEDs [9-12].

Generally, ideal host materials are required to fulfill several requirements $[13,14]$ : i) the triplet energy level $\left(E_{\mathrm{T}}\right)$ should be higher for efficient energy transfer to the guest; ii) suitable energy levels appropriately aligned with those of the neighboring active layers for efficient charge carrier injection to achieve a low operating voltage; iii) good and balanced charge carrier transport properties for the hole-electron recombination process; iv) good thermal and morphological stability for the vacuum deposition method to prolong the device operational lifetime.

Carbazole groups are widely used in host materials because of their high triplet energy levels and high hole mobility [15]. The Lee group [16] linked carbazolyl groups to diphenyl phosphoramines to design asymmetric (9-phenyl-9H-carbazole-2,5diyl)bis(diphenylphosphine oxide) (PCPOs) with a higher triplet energy level $(2.80 \mathrm{eV})$ and a glass transition temperature $\left(140{ }^{\circ} \mathrm{C}\right)$. The maximum external quantum efficiency (EQE) of PhOLEDs was $31.4 \%$, which was prepared by PCPO as a bipolar host material. Kim et al. [17] reported that the bipolar host material 9-(4-(9H-pyrido[2,3-b]indol-9-yl)phenyl)-9H-3,9'bicarbazole $(\mathrm{pBCb} 2 \mathrm{Cz})$ has a high triplet energy level $(2.93 \mathrm{eV})$, which is the main material of blue PhOLEDs, and the $\mathrm{EQE}$ of the device is $23.0 \%$. The Suh group [18] reported that the EQE of the prepared device of the bipolar host material $N$-(3,5-di(9H-carbazol-9-yl)phenyl)- $N$-(pyridin-2-yl)pyridin-2amine (DCPPy) based on carbazole group is $21.6 \%$. The Wang group [19] designed a host material with symmetrical structure based on phenothiazine-5,5-dioxide. But the host materials with asymmetric structure based on the phenothiazine-5,5-dioxide were rarely reported. For obtaining a high triplet energy level and good stability, herein, with phenothiazine-5,5-dioxide as acceptor (A) and carbazole as donor (D), and introducing an alkane chain group to the host materials for better film-forming properties, two novel blue phosphorescent host materials, CEPDO and CBPDO, were synthesized. At the same time, the photophysical properties, electrochemical properties and their thermal stability were studied and the expected results were obtained.

\section{Results and Discussion Synthesis and theoretical calculations}

The synthesis route for CEPDO and CBPDO is shown in Scheme 1 . The detailed synthesis procedures and characterizations are given in Supporting Information File 1.

In order to further understand the structural properties of the materials and the possibility of charge transfer from donor to acceptor on electronic excitation, the electronic structure of the materials were analyzed by density functional theoretical (DFT) calculations using the Gaussian 09 program package. The electron density distributions and energy levels of the HOMO and LUMO are displayed in Figure 1.

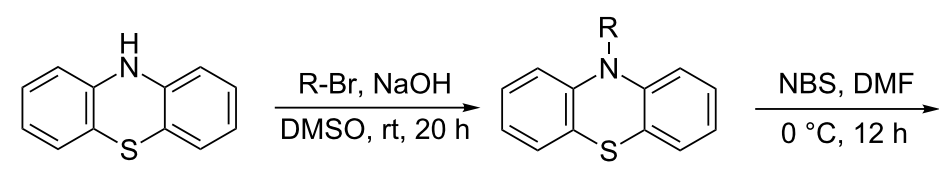

1a, 1b<smiles>[R]N1c2ccccc2Sc2cc(Br)ccc21</smiles>

2a, 2b<smiles>[R]N1c2ccccc2S(=O)(=O)c2cc(Br)ccc21</smiles>

3a, $\mathbf{3 b}$ $78.5 \%, 48.0 \%$

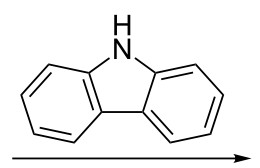

Cul, $\mathrm{K}_{3} \mathrm{PO}_{4}$ 1,4-dioxane $110^{\circ} \mathrm{C}, 24 \mathrm{~h}$<smiles>[R]N1c2ccccc2S(=O)(=O)c2cc(-n3c4ccccc4c4ccccc43)ccc21</smiles>

a: $\mathrm{R}=\mathrm{C}_{2} \mathrm{H}_{5}$ (CEPDO) (28.3\%)

b: $\mathrm{R}=\mathrm{C}_{4} \mathrm{H}_{9}$ (CBPDO) $(51.2 \%)$ 


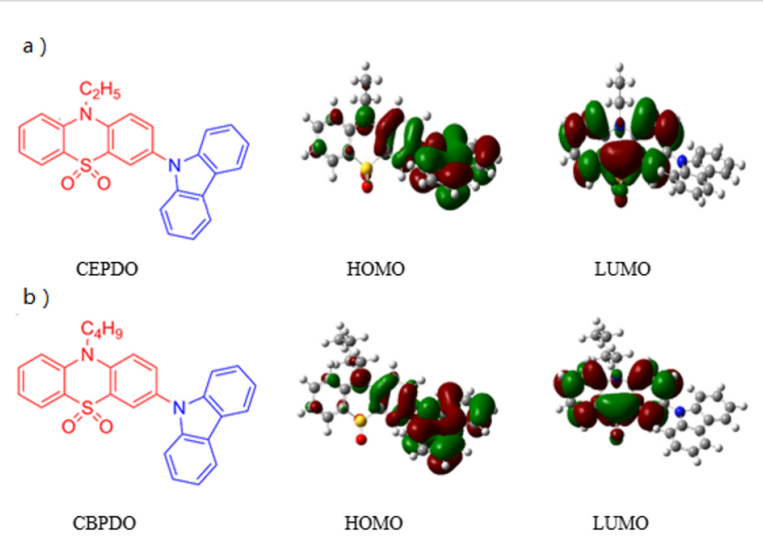

Figure 1: Structures and molecular orbitals of (a) CEPDO and (b) CBPDO.

The HOMOs of CEPDO and CBPDO are mainly distributed over the electron-donating carbazole moiety and slightly extended to the phenyl ring. The LUMOs are mostly localized on the phenothiazine-5,5-dioxide, based on the DFT calculation. There is a small degree of spatial overlap between the HOMO and LUMO in these two molecules. The separated HOMO and LUMO resulted from the strong electron-donating nature of the carbazole unit and electron-withdrawing ability of the phenothiazine-5,5-dioxide unit, thus realized the orbital separation of hole and electron transport in the same molecule. This indicated CEPDO and CBPDO have bipolar characteristic.

\section{Photophysical properties}

Figure 2 presents the UV-vis absorption, photoluminescence and phosphorescence ( $77 \mathrm{~K}$ ) spectra of CEPDO (a) and CBPDO (b) in solution, respectively. Obviously, the strong absorption peak at $236 \mathrm{~nm}$ can be ascribed to the $\pi \rightarrow \pi^{*}$ transition of carbazole moiety of the molecules, and the weaker absorptions around $295 \mathrm{~nm}$ assign to the $\mathrm{n} \rightarrow \pi^{*}$ transition of the conjugation of the whole molecule.

The optical bandgap $\left(E_{\mathrm{g}}\right)$ of the two substances were all calculated to be $3.32 \mathrm{eV}$ from the UV-vis absorption spectra of CEPDO and CBPDO. Upon photoexcitation of $330 \mathrm{~nm}$ at room temperature, both CEPDO and CBPDO exhibited a FL spectrum with peaks at $408 \mathrm{~nm}$ and emitted blue fluorescence. The fluorescence quantum efficiencies $(\Phi)$ of CEPDO and CBPDO were $62.5 \%$ and $59.7 \%$, respectively, by using quinine sulfate as a reference [20]. Compared with CEPDO, the longer alkyl chain of CBPDO led to a corresponding increase in $\Phi$ value. Therefore, CEPDO and CBPDO are promising photoelectric materials. To obtain the triplet energy level, their low-temperature Phos spectra were measured in a 2-methyltetrahydrofuran solution at $77 \mathrm{~K}$ which are also shown in Figure 2. The phosphorescence emission peaks were at $440 \mathrm{~nm}$ and $439 \mathrm{~nm}$, respectively. According to the onset of their phosphorescence spectra, the calculated triplet energy levels $\left(E_{\mathrm{T}}\right)$ of CEPDO and CBPDO were identical at $2.82 \mathrm{eV}$, which matched with the blue phosphorescent guest material FIrpic $(2.65 \mathrm{eV})$, dark blue phosphorescent guest material FCNIrpic (2.74 eV) and FIr6 $(2.73 \mathrm{eV})$. The high $E_{\mathrm{T}}$ was attributed to the insulated carbazole moieties. Hence, both CEPDO and CBPDO are expected to be applied to PhOLED as a blue phosphorescent host material.

\section{Electrochemical properties}

The electrochemical properties of CEPDO and CBPDO were studied by cyclic voltammetry (CV) measurements in deoxygenated DCM solution with $0.1 \mathrm{M}$ tetrabutylammonium hexafluorophosphate as the supporting electrolyte. The cyclic voltammograms are shown in Figure 3.
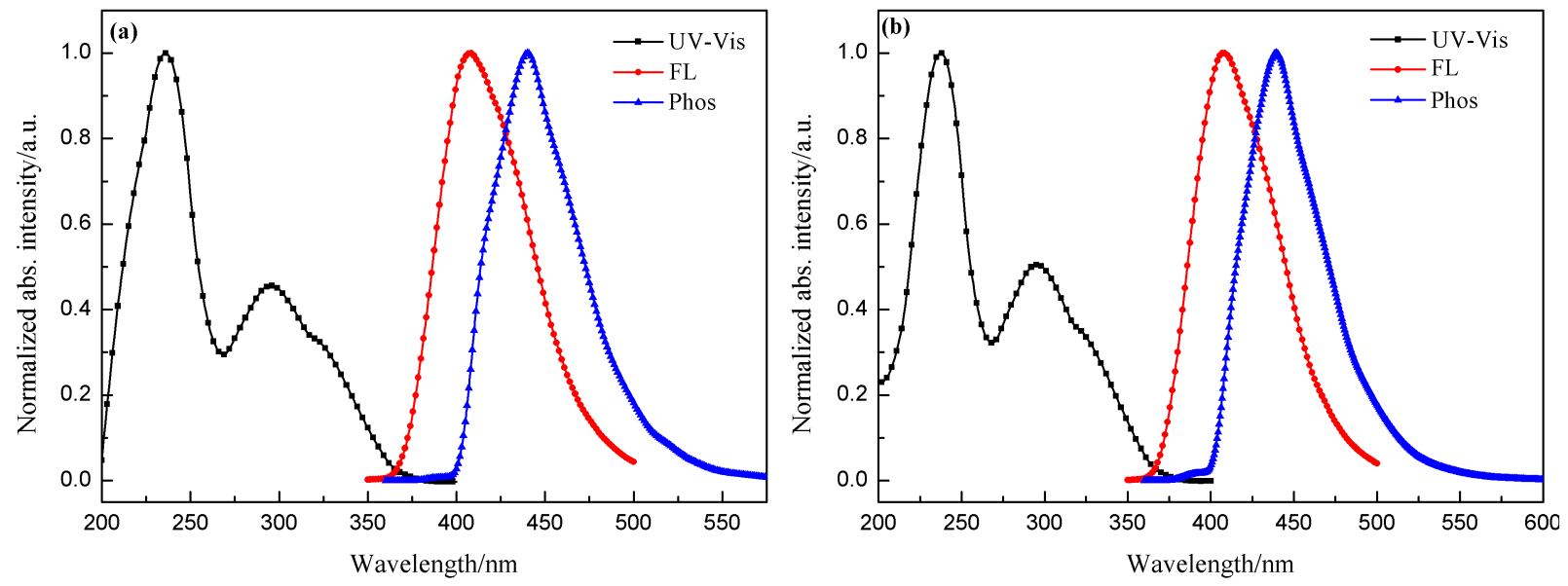

Figure 2: UV-vis absorption and photoluminescence spectra in DCM solution $\left(1 \times 10^{-5} \mathrm{M}\right.$ and $1 \times 10^{-6} \mathrm{M}$, respectively) at room temperature, phosphorescence spectra in 2-MeTHF solution $\left(1 \times 10^{-3} \mathrm{M}\right)$ at $77 \mathrm{~K}$ of CEPDO (a) and CBPDO (b). 


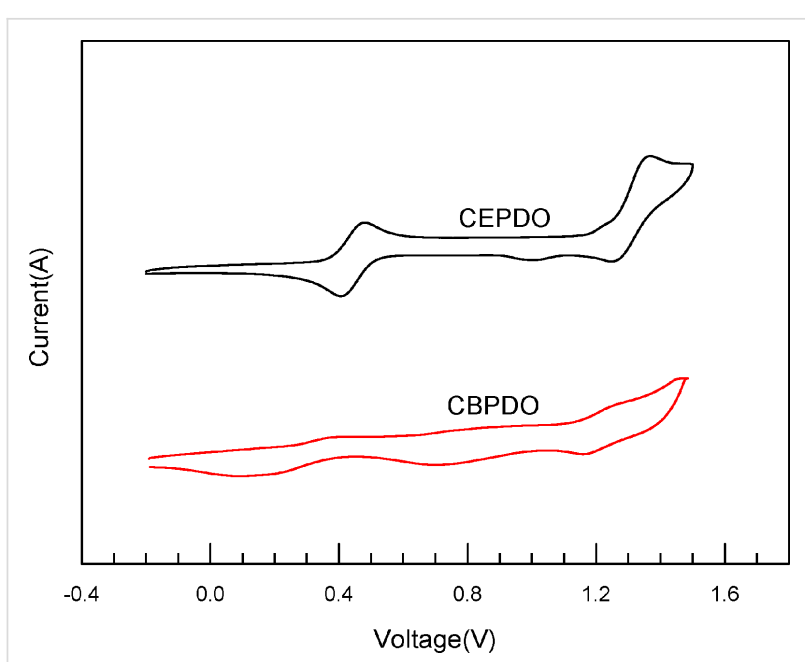

Figure 3: Cyclic voltammograms for CEPDO and CBPDO in DCM solution.

Cyclic voltammetry was measured with a glassy carbon working electrode, a platinum wire counter electrode, a saturated $\mathrm{Ag} / \mathrm{AgCl}$ reference electrode, ferrocenium-ferrocene $\left(\mathrm{Fc}^{+} / \mathrm{Fc}\right)$ as the internal standard and tetrabutylammonium hexafluorophosphate $(0.1 \mathrm{M})$ as the supporting electrolyte.

The onset potential ( $E_{\text {onset }}^{\text {ox }}$ ) of the first oxidation wave for CEPDO and CBPDO are utilized to estimate the HOMO energy level according to the equation $E_{\mathrm{HOMO}}=-e\left(E_{\text {ox }}^{\text {onset }}+4.8\right)$ as ca. -5.63 and $-5.64 \mathrm{eV}$, respectively. And both HOMO energy levels are matched with the functional function of the anode ITO $(-4.5$ to $-5.0 \mathrm{eV})$. The LUMO energy levels of CEPDO and CBPDO are estimated from the half-potential to be $-2.31 \mathrm{eV}$ and $-2.32 \mathrm{eV}$, respectively, which are matched with the LUMO energy level of electron injection material TAZ and favorable for electron injection and transmission [21]. There- fore, we successfully synthesized two novel bipolar host materials with higher triplet energy by choosing suitable donor and acceptor units.

\section{Thermal properties}

The thermal properties of CEPDO and CBPDO were determined by thermogravimetric analysis (TGA) and differential scanning calorimetry (DSC) under nitrogen atmosphere at a scanning rate of $10{ }^{\circ} \mathrm{C} / \mathrm{min}$ and the results are shown in Figure 4. Both CEPDO and CBPDO show very high thermal stability with decomposition temperatures $\left(T_{\mathrm{d}}\right)$ of 409 and $396{ }^{\circ} \mathrm{C}$ and glass transition temperatures $\left(T_{\mathrm{g}}\right)$ of 167 and $138{ }^{\circ} \mathrm{C}$, respectively. Compared to the introduction of ethyl groups, the introduction of normal butyl groups to the phenothiazine-5,5-dioxide moieties appears to decrease the $T_{\mathrm{d}}$ and $T_{\mathrm{g}}$ of CEPDO by $13{ }^{\circ} \mathrm{C}$ and $29{ }^{\circ} \mathrm{C}$, respectively, relative to those of CBPDO. The reason may be the $n$-butyl chain is longer. It reduces the polarity and intermolecular forces of molecules. The high thermal values ensure high thermostability and that the amorphous structure can form homogeneous and stable films by vacuum deposition to improve the lifetime of the PhOLEDs. The photophysics, electrochemical and thermal properties of CEPDO and CBPDO are summarized in Table 1.

\section{Conclusion}

In summary, we have designed and synthesized two bipolar host materials CEPDO and CBPDO. CEPDO and CBPDO not only have a high triplet energy but also show a bipolar behavior. Moreover, their fluorescence emission peaks are blue fluorescence at $408 \mathrm{~nm}$ and the fluorescence quantum efficiency $(\Phi)$ of CEPDO and CBPDO are $62.5 \%$ and $59.7 \%$, respectively. Both CEPDO and CBPDO show very high thermal stability with $T_{\mathrm{d}}$ of 409 and $396^{\circ} \mathrm{C}, T_{\mathrm{g}}$ of 167 and $138^{\circ} \mathrm{C}$, respectively, and also appear suitable HOMO and LUMO energy levels. Hence,
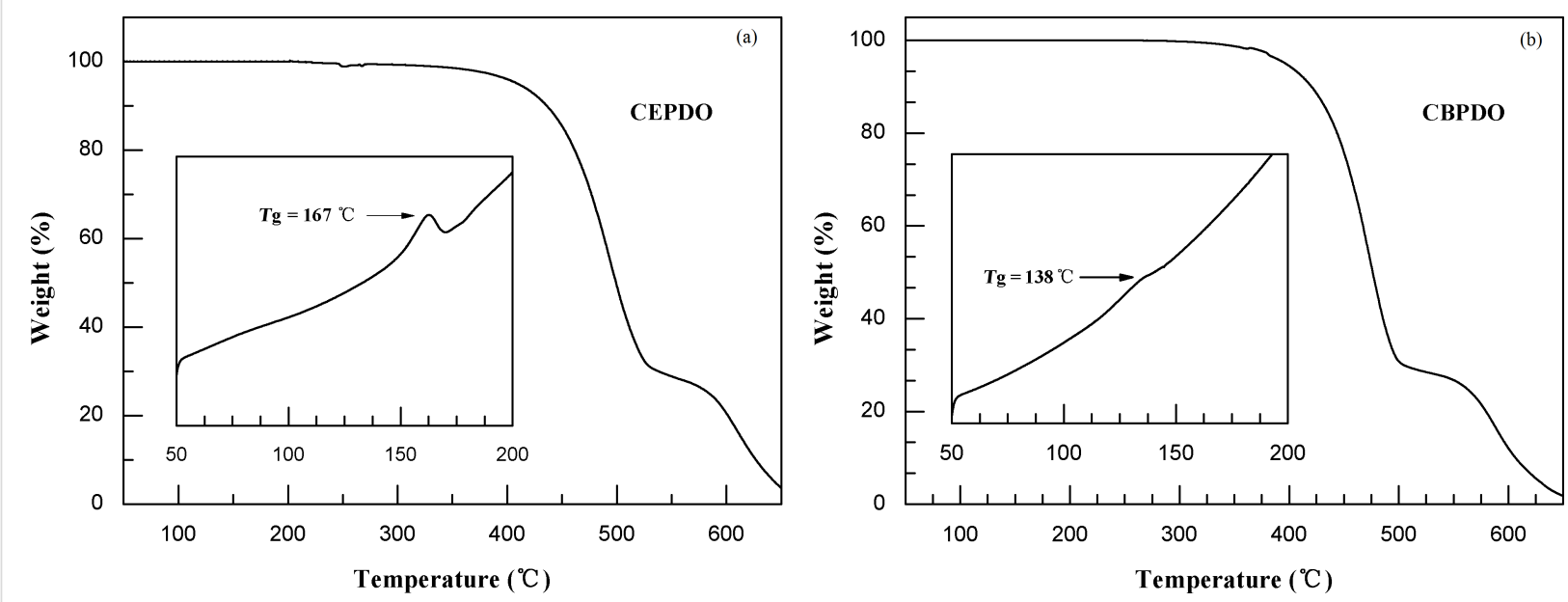

Figure 4: DSC and TGA curves of CEPDO and CBPDO. 
Table 1: Photophysics, electrochemical and thermal properties of CEPDO and CBPDO.

\begin{tabular}{|c|c|c|c|c|c|c|c|c|c|c|}
\hline compound & $\begin{array}{l}\lambda_{\mathrm{abs}^{\mathrm{a}}} \\
/ \mathrm{nm}\end{array}$ & $\begin{array}{l}\lambda_{\text {onset }}{ }^{\mathrm{b}} \\
/ \mathrm{nm}\end{array}$ & $\begin{array}{l}\lambda_{\mathrm{emt}}^{\mathrm{c}} \\
/ \mathrm{nm}\end{array}$ & $\begin{array}{l}\lambda_{\text {phos }}{ }^{\mathrm{d}} \\
/ \mathrm{nm}\end{array}$ & $\begin{array}{l}\Phi^{\mathrm{e}} \\
/ \%\end{array}$ & $\begin{array}{l}\text { Eonset }^{\mathrm{f}} \\
l \mathrm{eV}\end{array}$ & $\begin{array}{l}E_{\mathrm{g}} \mathrm{g} \\
\mathrm{leV}\end{array}$ & $\begin{array}{l}E_{\mathrm{t}}^{\mathrm{h}} \\
/ \mathrm{eV}\end{array}$ & $\begin{array}{l}E_{\mathrm{HOMO} / \mathrm{LUMO}}{ }^{\mathrm{i}} \\
\mathrm{leV}\end{array}$ & $\begin{array}{l}T_{\mathrm{d} / \mathrm{g}^{\mathrm{j}}} \\
/^{\circ} \mathrm{C}\end{array}$ \\
\hline CEPDO & 236 & 373 & 408 & 440 & 49 & 1.23 & 3.32 & 2.82 & $-5.63 /-2.31$ & $409 / 167$ \\
\hline CBPDO & 236 & 372 & 408 & 439 & 69 & 1.24 & 3.32 & 2.82 & $-5.64 /-2.32$ & $396 / 138$ \\
\hline
\end{tabular}

${ }^{a}$ The absorption maximum of the UV-vis spectrum; ${ }^{b}$ estimated from the onset of the UV-vis spectrum; ${ }^{c}$ emission fluorescence maximum at room

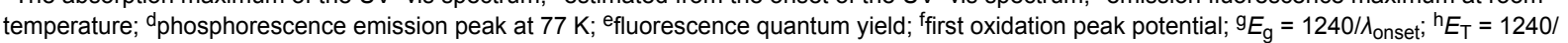
$\lambda_{\text {phos; }}{ }^{i} E_{\mathrm{HOMO}}$ : measured from the oxidation potential in $10^{-3} \mathrm{M} \mathrm{DCM}$ solution by cyclic voltammetry, $E_{\mathrm{LUMO}}=E_{\mathrm{g}}+E_{\mathrm{HOMO}}$; ${ }^{\mathrm{j}} \mathrm{decomposition}$ temperature $\left(T_{\mathrm{d}}\right)$ with $5 \%$ loss, glass transition temperature $\left(T_{\mathrm{g}}\right)$.

CEPDO and CBPDO are two promising blue phosphorescent host materials for PhOLEDs.

\section{Supporting Information}

\section{Supporting Information File 1}

Experimental part and copies of NMR spectra.

[https://www.beilstein-journals.org/bjoc/content/

supplementary/1860-5397-14-73-S1.pdf]

\section{Acknowledgements}

We acknowledge financial supports from the National Natural Science Foundation of China (No. 61705154), the Project of natural science Foundation of the Jiangsu Higher Education Institutions, (No. 17KJB140022); Suzhou University of Science and Technology (No. 331512301), the Natural Science Foundation of Jiangsu Province (No. BK20150282), Applied Basic Research Project of Suzhou (No. SYG201440), Graduate Research and Innovation Project of Jiangsu Province (SKCX16_060).

\section{ORCID ${ }^{\circledR}$ iDs}

Qiang Zhang - https://orcid.org/0000-0002-8173-8722

\section{References}

1. Tang, C. W.; VanSlyke, S. A. Appl. Phys. Lett. 1987, 51, 913-915. doi:10.1063/1.98799

2. Rajamalli, P.; Senthilkumar, N.; Gandeepan, P.; Huang, P.-Y.; Huang, M.-J.; Ren-Wu, C.-Z.; Yang, C.-Y.; Chiu, M.-J.; Chu, L.-K.; Lin, H.-W.; Cheng, C.-H. J. Am. Chem. Soc. 2016, 138, 628-634. doi:10.1021/jacs.5b10950

3. Baldo, M. A.; O'Brien, D. F.; You, Y.; Shoustikov, A.; Sibley, S.; Thompson, M. E.; Forrest, S. R. Nature 1998, 395, 151-154. doi:10.1038/25954

4. Lin, T.; Zhang, T.; Song, Q.; Jin, F.; Liu, Z.; Su, Z.; Luo, Y.; Chu, B.; Lee, C. S.; Li, W. Org. Electron. 2016, 38, 69-73. doi:10.1016/j.orgel.2016.08.001

5. Kim, K.-H.; Yoo, S.-J.; Kim, J.-J. Chem. Mater. 2016, 28, 1936-1941. doi:10.1021/acs.chemmater.6b00478

6. Feng, M. Q.; Tang, J. X.; Liao, L. S. Imaging Sci. Photochem. 2017, 35, 26-33.
7. Dos Santos, P. L.; Ward, J. S.; Bryce, M. R.; Monkman, A. P. J. Phys. Chem. Lett. 2016, 7, 3341-3346. doi:10.1021/acs.jpclett.6b01542

8. Wang, F.; Tao, Y.; Huang, W. Acta Chim. Sin. 2015, 73, 9-22. doi:10.6023/A14100716

9. Xiao, L.; Chen, Z.; Qu, B.; Luo, J.; Kong, S.; Gong, Q.; Kido, J. Adv. Mater. 2011, 23, 926-952. doi:10.1002/adma.201003128

10. Seino, Y.; Sasabe, H.; Pu, Y.-J.; Kido, J. Adv. Mater. 2014, 26, 1612-1616. doi:10.1002/adma.201304253

11. Tao, Y.; Yang, C.; Qin, J. Chem. Soc. Rev. 2011, 40, 2943-2970. doi:10.1039/c0cs00160k

12. Chaskar, A.; Chen, H.-F.; Wong, K.-T. Adv. Mater. 2011, 23, 3876-3895. doi:10.1002/adma.201101848

13. Zhao, Z.; Yu, G.; Chang, Q.; Liu, X.; Liu, Y.; Wang, L.; Liu, Z.; Bian, Z.; Liu, W.; Huang, C. J. Mater. Chem. C 2017, 5, 7344-7351. doi:10.1039/C7TC01594A

14. Sun, Q.; Cui, L.-S.; Xie, Y.-M.; Liang, J.-J.; Jiang, Z.-q.; Liao, L.-s.; Fung, M.-K. Org. Electron. 2017, 48, 112-117. doi:10.1016/j.orgel.2017.05.034

15. Baryshnikov, G. V.; Bondarchuk, S. V.; Minaeva, V. A.; Ågren, H.; Minaev, B. F. J. Mol. Model. 2017, 23, 55. doi:10.1007/s00894-017-3234-y

16. Kim, M.; Lee, J. Y. Adv. Funct. Mater. 2014, 24, 4164-4169. doi:10.1002/adfm.201304072

17. Kim, S. J.; Kim, Y. J.; Son, Y. H.; Hur, J. A.; Um, H. A.; Shin, J.; Lee, T. W.; Cho, M. J.; Kim, J. K.; Joo, S.; Yang, J. H.; Chae, G. S.; Choi, K.; Kwon, J. H.; Choi, D. H. Chem. Commun. 2013, 49, 6788-6790. doi:10.1039/c3cc42569j

18. Park, S.-R.; Kim, S.-M.; Kang, J.-H.; Lee, J.-H.; Suh, M. C. Dyes Pigm. 2017, 141, 217-224. doi:10.1016/j.dyepig.2017.02.014 19.Zheng, Y.; Xie, Q.; Wang, B. Chin. J. Org. Chem. 2015, 36, 803-811. 20. Yang, X.; Pan, Z. T.; Ma, Y. J. Anal. Sci. 2003, 16, 588-589. 21. Li, J.; Zhang, Z.; Han, C.; Ding, D.; Zhao, Y.; Huang, W.; Xu, H. J. Mater. Chem. C 2015, 3, 6709-6716. doi:10.1039/C5TC01179E 


\section{License and Terms}

This is an Open Access article under the terms of the Creative Commons Attribution License

(http://creativecommons.org/licenses/by/4.0), which permits unrestricted use, distribution, and reproduction in any medium, provided the original work is properly cited.

The license is subject to the Beilstein Journal of Organic Chemistry terms and conditions:

(https://www.beilstein-journals.org/bjoc)

The definitive version of this article is the electronic one which can be found at:

doi:10.3762/bjoc. 14.73 